\title{
Avaliação de competências de Agentes Comunitários de Saúde para coleta de dados epidemiológicos
}

\author{
Assessment of competencies of community health workers \\ for epidemiological data collection
}

Juliana de Oliveira Musse ${ }^{1}$ Roberta Smania Marques ${ }^{1}$ Fernando Rocha Lucena Lopes ${ }^{1}$ Karolinne Souza Monteiro ${ }^{1}$ Silvana Cristina dos Santos ${ }^{1}$

Programa de Mestrado em Saúde Pública, Universidade Estadual da Paraíba. R Baraúnas s/n/Prédio da Central de Integração Acadêmica/sala 329, Bairro Universitário. 58429-500 Campina Grande PB Brasil. julimusse@hotmail.com

\begin{abstract}
The scope of this study was to assess competencies in terms of reading, comprehension and problem-solving using educational material created for epidemiological research on people with disabilities. A form with twenty multiple-choice questions was prepared and distributed to a sample of 348 community health workers (CHWs) in the State of Paraiba. The socioeconomic profile revealed that, within the sample, most of these CHWs are female, between 30-49 years of age, married or in a stable relationship, with two children and have graduated from high school. Over $98 \%$ of CHWs are government employees and more than half have been working for more than eight years in the same community, predominantly in the urban area. The score for overall performance evaluation ranged from 33 to 60 points, with the mean score of $53.44 \pm 4.88$ points. This means that the CHWs were able to resolve over $65 \%$ of the questions properly. The overall performance was positively correlated with education and negatively with age, having children and the time taken to complete high school education. The overall results indicate the increasing professionalization and education of the CHWs and their potential role as collaborators in basic scientific research to make generalizations about public health.
\end{abstract}

Key words Community health worker, Epidemiology, Competency-based education
Resumo Este trabalho objetivou avaliar as competências de leitura, interpretação de texto e resolução de problemas de um material didático criado para pesquisa epidemiológica sobre pessoas com deficiências. Uma avaliação contendo vinte questões de múltipla escolha foi desenvolvida e aplicada em uma amostra de 348 agentes comunitários de saúde no estado da Paraíba. A caracterização socioeconômica da amostra mostrou que a maior parte desses profissionais é constituída por mulheres, de 30 a 49 anos, casadas ou que mantêm união estável, com dois filhos e ensino médio completo. Mais de $98 \%$ dos ACS são concursados e atuam há mais de oito anos nesta profissão e predominantemente na zona urbana. A pontuação referente ao desempenho global na avaliação variou de 33 até 60 pontos, sendo obtida a média de $53,44 \pm 4,88$ pontos. Isto significa que os agentes foram capazes de resolver adequadamente mais de $65 \%$ das questões. O desempenho global mostrou correlação positiva com a escolaridade e negativa com a idade, ter filhos e o tempo de conclusão do ensino formal. O conjunto dos resultados aponta a crescente profissionalização e escolarização dos ACS, e seu potencial papel como colaborador em pesquisas científicas fundamentais para estabelecimento de generalizações sobre a saúde das populações.

Palavras-chave Agente Comunitário de Saúde, Epidemiologia, Educação baseada em competências 


\section{Introdução}

A produção de conhecimento epidemiológico e estabelecimento de políticas públicas dependem da qualidade da informação colhida junto às populações ${ }^{1-5}$. Com a criação de um Sistema de Informação em Saúde no Brasil, a partir de 1975, foi possível consolidar uma ferramenta de gestão de dados com o intuito de subsidiar a programação de ações de saúde ${ }^{2}$ como, por exemplo, o Sistema de Informação sobre Mortalidade (SIM) e o Sistema de Informação sobre Nascidos Vivos (SINASC). Em 1998, foi criado o Sistema de Informação da Atenção Básica (SIAB), cujos dados são recolhidos por meio de fichas de cadastramento e de acompanhamento das famílias pelo Agente Comunitário de Saúde (ACS) ${ }^{4,6}$. Mas essa informação colhida pelo ACS e, posteriormente, consolidada e disponibilizada em um banco de dados de acesso público (SIAB), é confiável para estabelecer generalizações sobre a saúde das populações?

A qualidade das informações colhidas pelos agentes tem sido questionada na literatura por inúmeras razões, uma das quais certamente está relacionada à sua formação técnico-científi$\mathrm{Ca}^{3,4,7,8}$. A título de exemplo, recentemente, nosso grupo de pesquisa submeteu um artigo, analisando dados disponibilizados pelo SIAB sobre pessoas com deficiência, a um dos mais conceituados periódicos brasileiro da área de saúde. O parecer foi desfavorável à publicação, pois os dados colhidos pelos ACS não teriam fidedignidade. Esse excerto ilustra a inusitada situação de existir um banco de dados de acesso público criado e mantido com investimentos do Estado, o qual não atende requisitos necessários para produção de conhecimento científico.

Apesar desse debate sobre as competências necessárias para realizar coleta de informação que possa sustentar a produção de conhecimento epidemiológico, não se pode negar que os ACS são profissionais estratégicos nesse processo, devido a sua inserção na comunidade. De acordo com dados do Departamento de Atenção Básica (DAB) do Ministério da Saúde (MS), até o mês de janeiro de 2013, havia no Brasil 488.745 agentes de saúde em 5.411 municípios ${ }^{9}$. Esses profissionais realizam visitas mensais às famílias pelas quais são responsáveis e isto lhes permite oportunidade única de conhecimento das condições de saúde das populações, podendo potencialmente exercer diferentes papéis em pesquisas epidemiológicas.

O reconhecimento da profissão de ACS, por meio da Lei 10.507 , de $2002^{10}$, tem sido acompanhado por políticas específicas de formação continuada. Em 2004 foi proposto Referencial Curricular para o Curso Técnico de Agente Comunitário de Saúde, baseado no perfil de competências e habilidades que o profissional em nível técnico deveria desenvolver para atuar nessa profissão, tais como: propor e participar da implementação de ações intersetoriais e das políticas sociais governamentais; realizar o cadastramento das famílias na sua microárea; consolidar e analisar os dados obtidos pelo cadastramento, entre muitas outras. Esse documento baseia-se nos ideais de que as competências são mais do que "estoques de saberes", pois elas estão inseridas nas dimensões expressas nos conhecimentos (saberconhecer), nas habilidades (saber-fazer) e nas atitudes (saber-ser) ${ }^{11}$. Nesta perspectiva, o ACS tem de aprender a mobilizar essas competências nos espaços sociais para promover saúde e prevenir morbidades; ou seja, além de compreender o processo saúde-doença, ele tem que saber orientar, identificar e acompanhar diferentes pessoas e grupos de risco, de acordo com suas características e necessidades, incluindo a promoção da saúde da pessoa com deficiência ${ }^{12}$.

Nesta pesquisa, propusemo-nos a avaliar determinadas competências essenciais à participação dos ACS em pesquisas epidemiológicas, qual seja a sua capacidade de leitura e interpretação de texto; aplicação de conceito e resolução de problemas. Tais competências são fundamentais para inseri-los em projetos de formação continuada e proposição de parcerias para execução de pesquisas e diagnósticos sobre temáticas de relevância para o SUS.

Nosso grupo de pesquisa, o Núcleo de Estudos em Genética e Educação da Universidade Estadual da Paraíba (NEGE), desenvolveu um software chamado "Retrato Epidemiológico da Deficiência na Paraíba" (Redpb) ${ }^{13}$ para facilitar o cadastramento e gerenciamento de informações sobre pessoas com deficiência. Trata-se de uma iniciativa para melhor caracterização tanto das causas quanto das demandas por serviços especializados dessas pessoas. A coleta de dados e a alimentação do sistema serão feitas pelo ACS supervisionado pelos enfermeiros da ESF. Para otimização das atividades, haverá o treinamento de multiplicadores por meio de um curso de formação continuada à distância com uso de material didático de apoio e videoaulas à semelhança de um telecurso.

Face à intenção de envolver todos os agentes de saúde do estado da Paraíba nesse processo de coleta, e realizar a formação continuada sobre a temática da promoção da saúde de pessoas 
com deficiência, buscamos responder, neste trabalho, as seguintes perguntas: a) Os agentes de saúde compreendem as informações presentes no material didático e, portanto, possuem competências e habilidades de "aprender a aprender" necessários para a educação à distância? b) Os agentes de saúde são capazes de resolver situações -problema para coleta de informações fidedignas e que possam sustentar generalizações sobre a temática da deficiência? c) Que fatores poderiam interferir na compreensão do material didático e, portanto, na coleta de informação em campo?

\section{Procedimentos metodológicos}

\section{Características Gerais do Estudo}

Este é um estudo exploratório e descritivo de abordagem quantitativa ${ }^{14}$, realizado no município de Campina Grande (PB) que abriga uma população de 385.213 habitantes ${ }^{15}$, sede de uma das macrorregiões de saúde ${ }^{16}$. Até janeiro de 2013, o município contava com 79 Equipes da ESF e 646 ACS credenciados pelo MS, proporcionando Cobertura de $92,56 \%$ da população ${ }^{17}$.

A amostra deste estudo foi constituída por 348 ACS selecionados por conveniência, tendo em vista que sua participação no projeto de pesquisa foi voluntária. Essa amostra de agentes representa $54 \%$ dos que se encontra em serviço em Campina Grande (PB). Todos os ACS foram convidados a participar da ação de formação continuada que consistiu na leitura de textos do material didático que fundamentará a aplicação do projeto do Redpb e a resolução de vinte questões de múltipla escolha. Para a coleta dos dados foram elaborados dois instrumentos:

a) Questionário para caracterizar o perfil socioeconômico do ACS, contendo informações sobre: sexo, idade, situação conjugal, número de filhos, escolaridade, tempo de conclusão ou interrupção do maior nível de estudo, renda, tempo de profissão, vínculo empregatício, entre outros.

b) Avaliação de múltipla escolha para mensurar as competências de leitura e interpretação de texto, aplicação de conceito e resolução de problemas. Essa avaliação servirá para formação continuada dos profissionais a fim de que eles possam realizar o levantamento de informação sobre pessoas com deficiência, conforme será explicado detalhadamente no item específico.

Ambos os instrumentos foram submetidos a um pré-teste, envolvendo 23 ACS do Município de Ingá $(\mathrm{PB})$. Tal procedimento permitiu verifi- car se os itens do instrumento eram compreensíveis e se a sequência das questões estava bem delineada ${ }^{14}$. Cumpridas essas etapas de testes e procedidas as alterações necessárias, os instrumentos foram aplicados; respeitando, evidentemente, aos preceitos éticos estipulados pela resolução no $196 / 96^{18}$. As ações do projeto foram iniciadas após aprovação pelo Comitê de Ética em Pesquisa com Seres Humanos da Universidade Estadual da Paraíba.

\section{Avaliação de Competências}

A avaliação de competências foi elaborada pelo grupo de pesquisa com o envolvimento de especialistas do campo da Educação e Ensino de Biologia (SS e RSM). Nessa avaliação, o ACS foi convidado a ler textos extraídos do material didático preparado para aplicação do software Redpb e responder questões de múltipla escolha. Como dito anteriormente, este software foi desenvolvido para cadastrar e gerenciar informações sobre pessoas com deficiência. O material didático é constituído por explicações sobre os fatores causais das deficiências, especialmente as de natureza genética; resultados obtidos pelo grupo de pesquisa sobre a caracterização e prevalência das deficiências no nordeste e informações sobre necessidades específicas dessas pessoas, como a tecnologia assistiva ${ }^{19-23}$.

Para avaliar a compreensão dos ACS sobre o material didático do Redpb, foram selecionados cinco excertos e elaboradas vinte questões. Cada uma delas continha quatro alternativas cujos valores variavam de acordo as características da afirmação utilizada como possível resposta. Todas as questões ofereciam ao participante a possibilidade dele responder "não sei ou não entendi o texto" e a essa alternativa foi atribuído sempre o valor zero. Para a alternativa que continha uma afirmação completamente falsa e, muitas vezes, baseada no "senso comum", foi atribuído um ponto; àquelas que eram parcialmente verdadeiras, dois pontos; e às completamente verdadeiras, três pontos. Com essa pontuação diferencial das alternativas, foi possível definir a variável dependente como sendo o "desempenho global", ou seja, a somatória das pontuações de todas as questões da avaliação que poderia variar, então, de zero a sessenta pontos.

As questões também foram classificadas de acordo com as competências necessárias para respondê-las adequadamente. Havia um grupo de competências relacionadas à "Interpretação de Texto e Aplicação de Conceito”. Quando o 
agente de saúde conseguia utilizar uma informação disponibilizada direta ou indiretamente no texto para responder à questão ou quando ele compreendia, deduzia, interpretava ou usava um conceito contido no texto, então foi considerado competente naquele requisito. $\mathrm{O}$ segundo grupo de competências foi descrito como "Resolução de Problemas" e diz respeito aos casos potencialmente reais a serem enfrentados no cotidia- no do agente de saúde para resolver os desafios propostos no Redpb. Cada um desses subgrupos de competências consistiu em uma variável de desempenho de grupo, com valores variando de zero a trinta pontos.

O conteúdo da avaliação, como dito anteriormente, foi basicamente aquele necessário para entender a problemática do software. No Quadro 1, a título de exemplificação, foi transcrito um

Quadro 1. Reprodução integral de um excerto do material didático de apoio do projeto "Retrato Epidemiológico da Deficiência na Paraíba" e das questões usadas para avaliar competências e habilidades dos agentes comunitários de saúde de Campina Grande (PB).

\section{TEXTO 2}

No estado do Rio Grande do Norte foi descoberta uma doença genética que causa uma deficiência física muito severa conhecida por Síndrome Spoan (Macedo-Souza et al., 2005 e 2008). As crianças afetadas já nascem com a mutação genética associada à doença, mas só apresentam os primeiros sintomas quando começam a andar, por volta dos dois anos de idade. Elas andam nas pontas dos pés devido a uma rigidez ou espasticidade das pernas. Depois, vão perdendo o controle sobre os movimentos, devido à degeneração dos nervos e acabam confinadas em uma cadeira de rodas entre os cinco e vinte anos. A perda do controle dos movimentos é progressiva e, com o tempo, elas podem desenvolver deformações nos pés e coluna. O termo Spoan é um acrônimo com os principais sintomas da doença em inglês: Spastic Paraplegia, Optic Atrophy and Neuropathy (Paraplegia Espástica, Atrofia Optica e Neuropatia). Essa doença afeta mais de oitenta pessoas de uma mesma família que descendem todos de um único ancestral portador da mutação genética e cujos descendentes se espalharam por mais de dez municípios diferentes (Serrinha dos Pintos, Pau dos Ferros, São Miguel, Coronel João Pessoa, Doutor Severiano, Encanto, Natal e Martins, no estado do Rio Grande do Norte; Sítio Milagres, no Ceará, Lagoa, na Paraíba e em São Paulo). Todas essas pessoas compartilham um mesmo pedaço do DNA, no qual existe uma mutação, que acaba por prejudicar a expressão de uma determinada proteína, dando origem aos diferentes sintomas que caracterizam a doença. Para encontrar essa alteração genética, pesquisadores da UEPB e do Centro de Estudos do Genoma Humano na Universidade de São Paulo investiram mais de dez anos em pesquisa. Todos os afetados pela síndrome Spoan são filhos de casais aparentados entre si e essas uniões têm relação com a manifestação da doença. Quer dizer, essa síndrome somente se manifesta se ambos os membros do casal portar a mutação vinda de um ancestral comum. Nosso DNA possui cerca de 25.000 genes ou "receitas" para proteínas. No caso das pessoas que têm a síndrome Spoan, como elas são filhas de casais consanguíneos (primos), então elas receberam uma cópia da receita alterada de cada um dos seus pais ou genitores. Se a pessoa receber duas receitas alteradas para a proteína, cada cópia de um de seus pais, então essa proteína acaba sendo expressa de forma diferente do normal e leva ao desenvolvimento da doença. Os parentes das pessoas com Síndrome Spoan têm risco de possuírem essa mutação genética e de transmiti-la para as próximas gerações. Por isto, é importante que elas saibam disso.

\section{Questões:}

5) O texto descreve uma deficiência causada por uma doença genética: a síndrome Spoan. As crianças com essa deficiência acabam confinadas em uma cadeira de rodas até a adolescência porque perdem a capacidade de se movimentar. Se o texto não tivesse afirmado que se tratava de uma doença genética, qual outra informação você poderia usar para chegar a essa conclusão?

A - Todos os afetados pela síndrome Spoan residem na região da Serrinha dos Pintos onde foi descoberta a doença.

$B$ - Todos os afetados pela síndrome Spoan não devem ter sido vacinados e por isso ficaram deficientes.

$C$ - Todos os afetados pela síndrome Spoan são filhos de casais aparentados e têm um ancestral em comum.

D - Não sei.

6) As pessoas acometidas por uma síndrome genética desenvolvem a doença progressivamente. Isso significa que ela manifestou a doença:

A - Repentinamente.

$B$ - Ao longo dos anos.

$C$ - Desde o nascimento.

D - Não sei.

7) Leia novamente o seguinte trecho: “Nosso DNA possui cerca de 25.000 genes ou "receitas" para proteínas. Todas essas pessoas compartilham um mesmo pedaço do DNA comum, no qual existe uma mutação, que acaba por prejudicar a expressão de uma determinada proteína, dando origem aos diferentes sintomas que caracterizam a doença”. Essa mesma explicação poderia ser resumida da seguinte maneira:

A - As pessoas com um defeito em uma "receita" (DNA) acabam deficientes.

$B$ - As pessoas com defeito na "receita" (proteína) acabam deficientes.

$C$ - As pessoas que possuem a "receita" (DNA) sem alterações acabam deficientes.

$D$ - Não entendi a informação e não sei como escolher uma alternativa adequada.

8) Todas as pessoas com essa deficiência física causada pela síndrome Spoan são filhas de casais aparentados. Você acha que o fato dos pais serem aparentados tem alguma coisa a ver com a manifestação da doença?

A - Talvez, porque existem casais sem parentesco e tem filhos deficientes, enquanto tem casais muito aparentados sem nenhum filho deficiente.

$B$ - Não, acho que o parentesco entre pais não tem relação nenhuma com a deficiência das crianças.

C - Sim, porque pessoas aparentadas possuem parte de seu DNA de um ancestral comum e isto aumenta a chance de terem mutações genéticas.

D - Não sei responder. 
dos excertos da avaliação e as quatro questões usadas para mensurar as competências e habilidades. Os outros textos e perguntas, bem como a ficha para coleta de dados socioeconômicos dos ACS, foram reproduzidos integralmente no material suplementar desse artigo.

\section{Processamento dos Dados e Análise Estatística}

Os dados foram codificados, duplamente digitados por pessoas diferentes, tabulados e submetidos à análise estatística por meio do software Statistical Package for Social Science (SPSS) versão 17. As variáveis preditoras contemplaram informações sociais, econômicas, laborais e motivacionais citadas anteriormente no questionário; enquanto a variável dependente utilizada foi o "desempenho", sendo ela obtida pela somatória da pontuação das questões da prova (desempenho global) ou pela somatória da pontuação referente a um conjunto de competências e habilidades específico (desempenho relativo à interpretação e aplicação de conceito e desempenho relativo à resolução de problemas).

Por um lado, os resultados mostram o perfil socioeconômico do ACS de Campina Grande feito por meio da análise estatística descritiva dos parâmetros avaliados. Por outro lado, os dados foram analisados para estabelecimento da distribuição dos escores de desempenho, a fim de se responder quais fatores influenciaram ou não no mesmo. Para tanto, inicialmente os dados foram explorados e, face à distribuição da variável de saída não ter sido normal, foram realizados testes não paramétricos com o nível de significância de 5\%.

\section{Resultados}

\section{Perfil dos Agentes Comunitários de Saúde}

A Tabela 1 mostra o perfil do Agente Comunitário de Saúde que atua no município de Campina Grande, na Paraíba. A maior parte desses profissionais é constituída por mulheres, entre 30 a 49 anos, casadas ou que mantêm união estável, com dois filhos e ensino médio completo. Mais de 98\% deles são concursados; 90\% iniciaram o curso técnico para ACS; mais da metade deles atua há mais de oito anos nesta profissão e predominantemente na zona urbana, tendo em vista que Campina Grande é a segunda maior cidade do estado e um pólo universitário. Talvez por essa razão, verifica-se que 32,2\% dos participan-
Tabela 1. Perfil socioeconômico dos ACS que atuam no município de Campina Grande (PB), 2013.

\begin{tabular}{|c|c|c|c|}
\hline & \multirow[b]{2}{*}{ Variável } & \multicolumn{2}{|c|}{ Frequência } \\
\hline & & $\mathbf{n}$ & $\%$ \\
\hline \multicolumn{4}{|l|}{$\operatorname{Sexo}(N=331)$} \\
\hline Feminino & & 282 & 85,2 \\
\hline Masculino & & 49 & 14,8 \\
\hline
\end{tabular}

Faixa Etária $(\mathrm{N}=348)$

$20-29$ anos

$50 \quad 14,0$

$30-39$ anos

$145 \quad 42,0$

$40-49$ anos

10831,0

Mais de 50 anos

$45 \quad 13,0$

Estado Civil $(\mathrm{N}=337)$

Solteiro, separado, divorciado ou viúvo $\quad 111 \quad 32,9$

Casado ou mantém união estável $\quad 226 \quad 67,1$

Número de Filhos ( $\mathrm{N}=348)$

0

1

$\begin{array}{lll}2 & 108 & 31,0\end{array}$

$3 \quad 44 \quad 13,0$

4 ou mais $\quad 19 \quad 9,0$

Escolaridade $(\mathrm{N}=348)$

Estudando no momento da pesquisa $\quad 67 \quad 19,3$

Não estão mais estudando $\quad 281 \quad 80,7$

Ensino Fundamental Completo $\quad 4 \quad 1,1$

Ensino Médio Incompleto $\quad 5 \quad 1,4$

Ensino Médio Completo $\quad 109 \quad 31,3$

Ensino Técnico Incompleto $\quad 34 \quad 9,8$

Ensino Técnico Completo $\quad 84 \quad 24,1$

Ensino Superior Incompleto $\quad 58 \quad 16,7$

Ensino Superior Completo $\quad 41 \quad 11,8$

Pós-Graduação Incompleta $\quad 6 \quad 1,7$

Pós-Graduação Completa $\quad 7 \quad 2,0$

Curso de Formação para ACS $(\mathrm{N}=346)$

Não realizaram nenhuma etapa $\quad 39 \quad 11,3$

Realizaram alguma etapa (Etapa 1 ou 2) $\quad 307 \quad 88,7$

Participou de projetos de pesquisa ou extensão $\quad 98 \quad 31,6$

Vínculo Empregatício $(\mathrm{N}=343)$

Sem contrato

Comissionado

Concursado

Tempo que atua como ACS $(\mathrm{N}=348)$

Menos de um ano

De 01 a 04 anos

De 05 a 08 anos

Mais de 08 anos

Zona Urbana

Zona Rural

tes iniciaram ou concluíram um curso superior; quase $4 \%$ estão fazendo ou já possuem pós-graduação; cerca de $30 \%$ já tinham participado de algum projeto de pesquisa ou extensão universitária e quase $20 \%$ continuam estudando. 
Da totalidade dos agentes de saúde do sexo feminino, $67 \%$ eram casadas ou mantinham união estável e $84 \%$ tinham filhos; enquanto os homens, apesar de terem constituído família em proporção semelhante $(68 \%)$, tinham menos filhos (67\%). A idade média das mulheres foi 39,05 $\pm 8,69$ anos e dos homens, $36,90 \pm 8,66$, entretanto, essa diferença não foi significativa $(\mathrm{p}=0,110)$.

A renda líquida familiar dos agentes de saúde variou de $R \$ 622,00$ até $R \$ 6.000,00$ e a média foi de R\$1860,57 $\pm \mathrm{R} \$ 939,88$; não tendo sido observada diferença significativa nas médias dos agentes do sexo masculino e feminino $(\mathrm{p}=0,28)$. A renda per capita variou de $\mathrm{R} \$ 135,00$ até $\mathrm{R} \$$ 2.000,00, sendo em média de $\mathrm{R} \$ 578,60 \pm \mathrm{R} \$$ 338,97 . Para fins de comparação, o salário mínimo considerado foi de $\mathrm{R} \$ 678,00$. Da totalidade dos entrevistados, $84 \%$ não referiram outra ocupação além de ser ACS.

Entre os agentes que estavam cursando ou concluíram o nível superior $(\mathrm{n}=99)$, predominaram os cursos na área das ciências humanas e sociais $(71,8 \%)$ em relação aos da área de saúde (20,2\%) e ciências exatas (8\%). Destacaram-se os seguintes cursos: Ciências da Computação ( $\mathrm{n}=$ 1), Química $(n=1)$, Estatística $(n=2)$, Teologia $(\mathrm{n}=2)$, Direito $(\mathrm{n}=3)$, Matemática $(\mathrm{n}=4)$, Letras $(\mathrm{n}=4)$, Ciências Contábeis e Economia $(\mathrm{n}=5)$, Administração $(\mathrm{n}=5)$, História $(\mathrm{n}=5)$, Enfermagem $(n=8)$, Geografia $(n=8)$, Biologia $(\mathrm{n}=12)$, Pedagogia (19), Ciências Sociais, Comunicação Social, Serviço Social e Filosofia ( $\mathrm{n}=$ 20). Isso mostra uma tendência à formação humanística entre esses profissionais, o que poderia indicar seu potencial para articular políticas de natureza social e econômica.

Mais da metade da população amostrada $(66,6 \%)$ estava cursando ou se formou na Universidade Estadual da Paraíba e 8\% nas Universidades Federais da região (Universidade Federal de Campina Grande, Universidade Federal da Paraíba e Universidade Federal de Pernambuco); tendo $34,4 \%$ dos agentes financiado sua formação em nível superior junto às instituições privadas de ensino. Esse resultado mostra que a principal instituição formadora dos ACS de Campina Grande é a UEPB.

\section{As competências do ACS}

As competências dos agentes comunitários de saúde de Campina Grande foram avaliadas, conforme descrito anteriormente, por meio de um instrumento com excertos de textos e perguntas de múltipla escolha. A pontuação referente ao desempenho global variou de 33 até 60 pontos, sendo obtida a média de $53,44 \pm 4,88$ pontos. Isto significa que os agentes foram capazes de resolver adequadamente mais de $65 \%$ das questões.

Na Figura 1 é possível observar a variação na mediana da pontuação de desempenho global e nos percentis obtidos para os diferentes graus de escolaridade dos agentes comunitários de saúde participantes deste estudo. A diferença na mediana de desempenho para quem tem ensino fundamental completo comparado com ensino médio é da ordem de dez pontos; e essa diferença é significativa estatisticamente quando feito o teste de Mann-Whitney ( $U=88,5 ; \mathrm{p}=0,021)$. Se comparadas as medianas entre grupo de agentes com ensino médio completo aos que concluíram o ensino superior, verifica-se que a diferença também é significativa ( $\mathrm{p}<0,0050)$. Observou-se, portanto, um aumento na pontuação de desempenho com a crescente escolarização do agente de saúde, como seria de se esperar; e os testes de correlação corroboram esse achado (Spearman $r$ $=0,308$ e $\mathrm{p}<0,01)$.

Verificou-se que quase $60 \%$ dos agentes têm de 20 a 39 anos, sendo adultos jovens, e que parte concluiu sua formação há pouco tempo. Para verificar se o desempenho do ACS era influenciado pela idade, foi realizado um teste de correlação. Os resultados mostraram correlação negativa (Spearman $\mathrm{r}=-0,39$; $\mathrm{p}<0,01$ ), ou seja, quanto mais jovem o agente de saúde, melhor o seu desempenho. Isto poderia ser explicado pelo fato dos agentes com mais idade terem concluído sua escolarização há mais tempo. Então, verificamos se a idade tinha também correlação com o tempo que o agente parou de estudar e com o desempenho. De fato, quanto maior a idade do agente, maior também o tempo em que concluiu sua escolarização e pior é o seu desempenho.

Outros fatores que poderiam influenciar no desempenho dos agentes são o estado civil e o fato de terem ou não filhos para cuidar. Quem é solteiro ou não tem família constituída, geralmente é mais jovem e tem mais tempo para dedicar-se aos estudos. Testes de correlação entre essas variáveis mostraram que o desempenho não é modificado em função do estado civil (Spearman $\mathrm{r}=0,56$ e $\mathrm{p}=0,3$ ); entretanto, ele foi melhor entre aqueles agentes sem filhos (Spearman $r=$ - 0,19 e p $<0,005)$. Constatou-se que o desempenho global não é diferente segundo o sexo do agente ou a zona, rural ou urbana, onde ele atua.

Outra hipótese testada foi se o desempenho global seria modificado pelo tempo de atuação na profissão de agente de saúde. Verificou-se que 


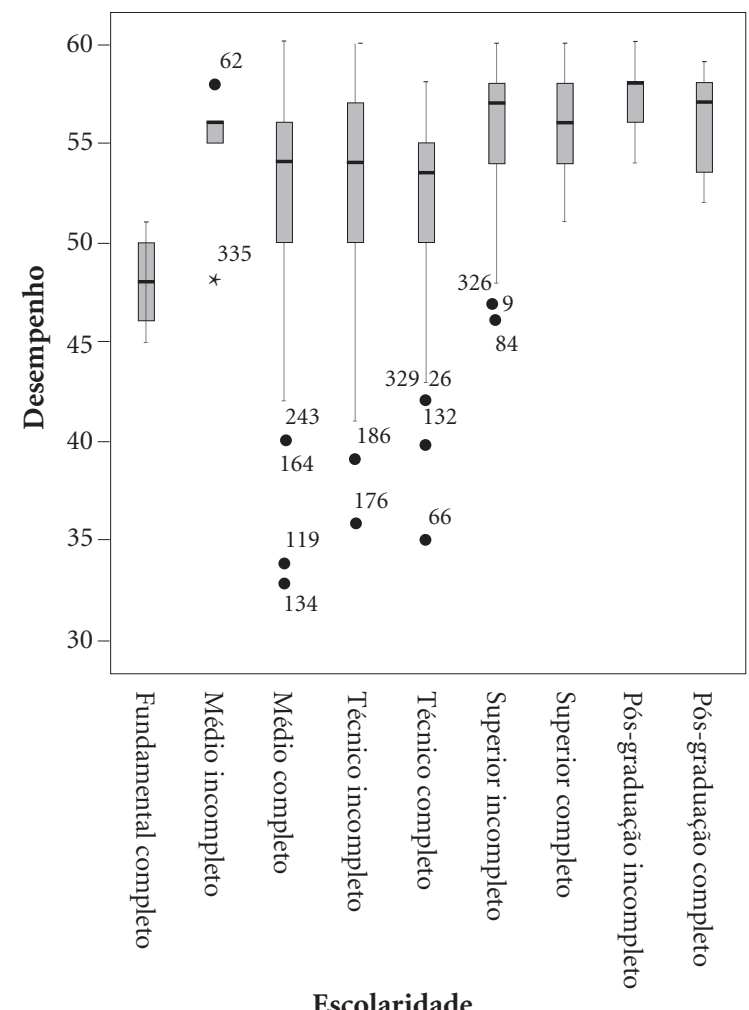

Figura 1. Diagrama de Caixa e Bigodes dos escores de desempenho global em relação aos diferentes graus de escolaridade dos agentes comunitários de saúde de Campina Grande (PB).

quanto mais tempo na profissão, menor é a pontuação na avaliação (Spearman $\mathrm{r}=-0,437$ e $\mathrm{p}<$ $0,005)$. Foi cogitada a possibilidade de o desempenho ter sido modificado pelo fato do ACS ter ou não dedicação exclusiva, ou seja, quem tem outra atividade remunerada poderia ter pior desempenho. O teste de Mann-Whitney mostrou que essa diferença não é significativa $(\mathrm{U}=7181$ e $\mathrm{p}=0,41$ ), embora a mediana para o grupo que tem outra atividade profissional seja maior do que para quem tem dedicação exclusiva.

Em relação aos aspectos motivacionais, foi levantada a hipótese de que o desempenho do agente de saúde poderia ser modificado pela sua experiência e vivência com pessoas com deficiência, tendo em vista que os textos da avaliação tratavam desse assunto. Uma das perguntas feitas no roteiro de entrevista é se o agente tinha ou não pessoas deficientes na sua família; e os resultados dos testes mostram que as diferenças nas medianas não foram significativas $(p=0,9)$. Ve- rificamos também se o desempenho tinha correlação com o número de pessoas com deficiência conhecidos na comunidade do ACS e, mais uma vez, essa correlação não foi significativa (Spearman $\mathrm{r}=0,08$ e $\mathrm{p}=0,878$ ).

\section{As diferentes competências dos ACS}

Uma das perguntas mais importantes deste trabalho é entender se os agentes de saúde são capazes de ler e interpretar textos para tomada de decisões na sua prática, ou seja, se conseguem "aprender a aprender" a partir de um curso à distância. A Figura 2 mostra a comparação das medianas de desempenho para os dois grupos de competências avaliados entre os participantes do estudo. Verifica-se uma tendência de melhor

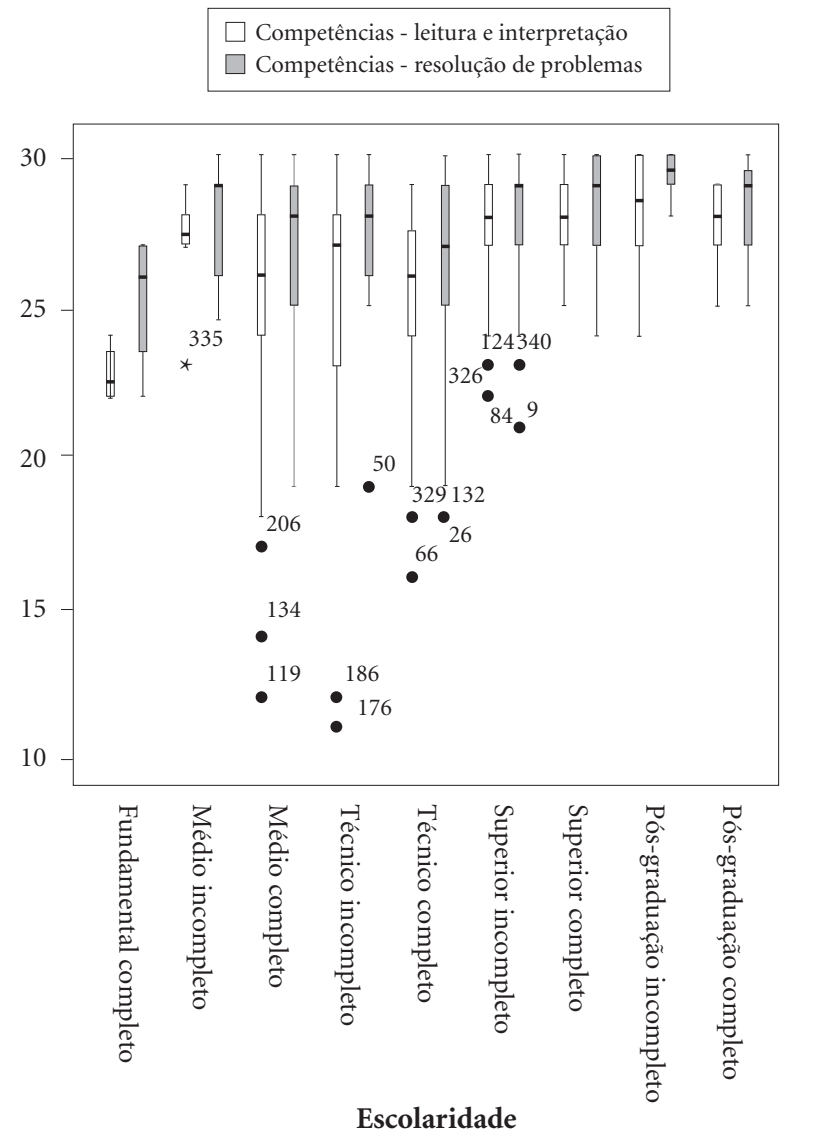

Figura 2. Diagrama de Caixa e Bigodes dos escores de desempenho para cada um dos grupos de competências e habilidades avaliados em relação ao diferentes graus de escolaridade dos agentes comunitários de saúde de Campina Grande (PB). 
desempenho dos agentes de saúde quando consideradas as questões de resolução de problemas em vez das de leitura e interpretação de texto. Ao fazer o teste de Friedman, verificaram-se diferenças significativas entre os escores médios dos dois grupos de competências para mesma população amostrada $(\mathrm{p}<0,005)$.

Esses resultados mostram que, mesmo os agentes com menor grau de escolaridade, conseguiram resolver aproximadamente $80 \%$ das situações problema com as quais terão de lidar para realizar a coleta de dados epidemiológicos sobre pessoas com deficiência. Trata-se, portanto, de uma evidência bastante consistente para se afirmar que é possível realizar a formação continuada dos agentes utilizando material didático planejado para esta finalidade. Para os agentes com melhor formação acadêmica, esses possíveis equívocos de compreensão e resolução de problemas se reduzem a menos de $10 \%$, o que pode ser ainda corrigido com a formação por videoaulas a ser implementada na execução da pesquisa.

\section{O conhecimento dos ACS: descrição dos resultados da avaliação}

A Tabela 2 mostra a frequência de respostas para cada uma das alternativas das questões elaboradas na avaliação de competências e habilidades do Redpb. A frequência de respostas do tipo "não sei" variou de 0 a $9,8 \%$, sendo menor do que $1 \%$ para mais da metade das questões. Ou seja, poucos assuntos foram incompreensíveis pelos agentes de saúde de Campina Grande. As questões que tiveram maior frequência da escolha "não sei" tratavam de assuntos específicos sobre a relação entre a genética e a deficiência: o entendimento sobre o que é DNA e sua função e resolver questões para estabelecimento de parentesco maior do que primeiro grau.

A frequência de respostas falsas ou de "erros" na compreensão de texto e resolução de problemas variou de 1,4 a $22,3 \%$, tendo uma média de $5 \%$. De forma surpreendente, as questões que mais os agentes se confundiram e optaram pela

Tabela 2. Frequência das respostas para cada uma das vinte questões da avaliação de competências e habilidades envolvendo agentes comunitários de saúde de Campina Grande (PB). As alternativas foram pontuadas de acordo com o seguinte critério: respostas "não sei" (0); falsas (1); parcialmente verdadeiras (2) e verdadeiras (3).

\begin{tabular}{|c|c|c|c|c|c|c|c|c|c|}
\hline \multirow{3}{*}{ Assuntos/Pontuação da questão } & \multicolumn{9}{|c|}{ Frequências das Alternativas por Questão } \\
\hline & \multicolumn{2}{|c|}{1} & \multicolumn{2}{|c|}{2} & \multicolumn{2}{|c|}{3} & \multicolumn{2}{|c|}{4} & \multirow[b]{2}{*}{$\mathbf{N}$} \\
\hline & n & $\%$ & $\mathbf{n}$ & $\%$ & $\mathbf{n}$ & $\%$ & $\mathbf{n}$ & $\%$ & \\
\hline $\begin{array}{l}\text { 1- Entender que o IBGE não oferece informação sobre as causas } \\
\text { das deficiências }\end{array}$ & 3 & 0,9 & 25 & 7,2 & 52 & 15 & 267 & 76,9 & 347 \\
\hline 2- Saber diferenciar fatores genéticos e ambientais & 0 & 0,0 & 28 & 8,1 & 0 & 0,0 & 319 & 91,9 & 347 \\
\hline 3- Vários afetados em uma família são indicio de doenças genéticas & 2 & 0,6 & 12 & 3,5 & 27 & 7,8 & 305 & 88,2 & 346 \\
\hline 4- Resolver problema sobre surdez de natureza genética & 1 & 0,3 & 11 & 3,2 & 36 & 10,3 & 300 & 86,2 & 358 \\
\hline 5- Relação entre parentesco e manifestação de doença genética & 8 & 2,3 & 23 & 6,6 & 12 & 3,5 & 304 & 87,6 & 347 \\
\hline 6- As doenças genéticas podem ser progressivas & 2 & 0,6 & 13 & 3,7 & 144 & 41,4 & 189 & 87,6 & 348 \\
\hline 7- O DNA é “receita” para as características & 34 & 9,8 & 19 & 5,5 & 155 & 44,7 & 139 & 40,1 & 347 \\
\hline 8- Relação da consanguinidade e deficiência & 3 & 0,9 & 11 & 3,2 & 26 & 7,5 & 307 & 88,5 & 347 \\
\hline 9- Risco de manifestação de doenças genéticas & 14 & 4,0 & 7 & 2,0 & 156 & 45 & 170 & 49 & 347 \\
\hline 10- Grau de parentesco e risco de prole com doença genética & 1 & 0,3 & 22 & 6,3 & 56 & 16,1 & 268 & 77,2 & 347 \\
\hline 11- Resolver problema sobre graus de parentesco & 2 & 0,6 & 5 & 1,4 & 18 & 5,2 & 320 & 92,8 & 345 \\
\hline 12- Resolver problemas sobre grau de parentesco & 30 & 8,6 & 13 & 3,7 & 205 & 59,1 & 99 & 28,5 & 347 \\
\hline 13- Papel do ACS na pesquisa epidemiológica & 0 & 0,0 & 5,0 & 1,4 & 43 & 12,4 & 299 & 86,2 & 347 \\
\hline 14- Papel do ACS no REDPB & 5 & 1,4 & 50 & 14,5 & 41 & 11,8 & 250 & 72,3 & 346 \\
\hline 15- Preenchimento fidedigno da ficha & 4 & 1,2 & 77 & 22,3 & 14 & 4,1 & 250 & 72,5 & 345 \\
\hline 16- Identificação de erros no cadastramento & 3 & 0,9 & 10 & 2,9 & 22 & 6,3 & 313 & 89,9 & 348 \\
\hline 17- Saber o que são malformações congênitas & 3 & 0,9 & 10 & 2,9 & 32 & 9,2 & 303 & 87,1 & 348 \\
\hline 18- Saber o que são doenças crônicas & 4 & 1,2 & 24 & 6,9 & 23 & 6,6 & 296 & 85,3 & 347 \\
\hline 19- Saber relacionar sofrimento fetal à deficiência & 1 & 0,3 & 7 & 2,0 & 15 & 4,3 & 325 & 93,4 & 348 \\
\hline 20- Diferenciar deficiências de causa ambiental & 3 & 0,9 & 12 & 3,5 & 6 & 1,7 & 326 & 93,9 & 347 \\
\hline
\end{tabular}


alternativa falsa diziam respeito à compreensão do seu papel na coleta de dados. Na questão 14, por exemplo, eles não entenderam que irão colher dados e, sim, que iriam indicar os pacientes aos pesquisadores; ou seja, não compreenderam claramente o seu papel na pesquisa. Na questão 15 , os ACS se equivocaram por acreditar que poderiam preencher as fichas com o conhecimento que já possuem sobre as famílias, sem entrevistá-las diretamente. Possivelmente, por serem membros da comunidade e conhecerem as famílias com as quais trabalharam por muito tempo; os ACS compartilham a prática de completar as fichas de dados com o que já sabem sobre o participante. Essa prática pode comprometer a fidedignidade do dado colhido em campo.

Em relação às questões parcialmente verdadeiras, muitas delas disponibilizaram conhecimentos de "senso comum" para o ACS. A intenção foi averiguar se o agente usaria o conhecimento dele da vida cotidiana ou aquele presente no texto. A questão 3, por exemplo, perguntava por que as doenças genéticas geralmente acometem várias pessoas da mesma família. A alternativa parcialmente verdadeira afirmava "porque essas doenças eram transmitidas pelo sangue da mãe". Na amostra, 7,8\% optou por essa alternativa, e $88,2 \%$ escolheram a alternativa adequada. Isto mostra que menos de $10 \%$ dos agentes usou conhecimento de "senso comum" e esse resultado se repetiu em outras perguntas que tiveram a mesma intenção como, por exemplo, nas questões 8 e 10

Outro achado interessante foi verificar a dificuldade dos agentes em relação à compreensão do conceito de risco e uso de porcentagens. A questão 9 afirmava que o risco de um casal aparentado ter um filho deficiente é da ordem de $13 \%$, enquanto um casal não aparentado, isto se reduz para $4 \%$ e se perguntava o que isto significava. Se todos os filhos desse casal seriam ou não deficientes. Somente $49 \%$ dos agentes escolheram a alternativa correta para essa pergunta.

A frequência das respostas corretas variou de $28,5 \%$ a $93,9 \%$, tendo uma frequência média de $77 \%$. A questão que eles mais erraram foi sobre classificação de parentesco de primos em segundo grau e a que eles mais acertaram foram as perguntas de resolução de problemas, as quais pediam para classificar o tipo de deficiência a partir de uma descrição de caso.

\section{Discussão}

O perfil socioeconômico do agente comunitário que atua em Campina Grande não é diferente daquele encontrado em outras regiões. O ACS geralmente é do sexo feminino, casada, com ensino médio completo e atua principalmente na zona urbana ${ }^{24-33}$. A maior parte desses agentes são adultos jovens (30 a 49 anos de idade) e isto pode ser um indicativo de que a profissão tem sido mais valorizada ${ }^{34}$ ou, diacronicamente, que se trata de uma alternativa temporária e oportuna de emprego ${ }^{35}$. Nossos resultados mostram que 92\% dos ACS atuam há mais de quatro anos na profissão e que $55 \%$ há mais de oito anos. Isto evidencia que ser agente de saúde tem configurado como uma opção de carreira ${ }^{33}$.

A média da renda per capita familiar dos ACS foi inferior a um salário mínimo caracterizando-os como uma população com baixa renda. Segundo Santos ${ }^{24}$, a política de saúde na qual o agente está inserido, sempre priorizou, desde a sua implantação, as áreas com baixos indicadores sociais e de saúde e, como os ACS geralmente pertencem a essas áreas, era de se esperar que figurassem nesses estratos de renda mais baixa.

Os resultados em relação ao grau de escolaridade demonstraram que a maior parte da população do estudo possui nível superior àquele preconizado pelo MS, com predomínio do ensino médio completo ( $82 \%$ ), seguido do superior $(15,5 \%)$. Esses dados corroboram estudo desenvolvido por Maia et al. ${ }^{25}$ no qual $85 \%$ de sua amostra haviam concluído o ensino médio e 10\% o ensino superior.

Embora o trabalho do ACS, inicialmente, fosse mais voltado para a educação em saúde sem a exigência de um conhecimento muito técnico e científico ${ }^{36}$, com o decorrer dos anos, o perfil desses profissionais mudou com sua crescente escolarização. Por exemplo, em estudo ${ }^{26}$ envolvendo uma amostra de 301 ACS do Rio de Janeiro, foi comparada a sua escolarização no momento de ingresso na profissão e quando da entrevista. Constatou-se uma considerável melhora no nível de instrução, pois os agentes com ensino fundamental passaram de 9,6\% para apenas $2,7 \%$ e $26 \%$ deles decidiram retomar seus estudos após ingressar na carreira. Na nossa pesquisa, cerca de 20\% dos ACS de Campina Grande estavam estudando no momento da entrevista.

Apesar da iniciativa do MS para garantir a formação técnica ${ }^{37-39}$, cerca de $11 \%$ dos agentes de Campina Grande não realizaram a primeira etapa do curso oferecido por eles e $89 \%$ nunca com- 
pletou a terceira etapa prevista. Isto é explicado porque o financiamento dessa primeira etapa é garantido pelo MS e os municípios e estados não conseguem viabilizar a sua continuidade ${ }^{40}$. Para alguns autores ${ }^{37,41}$, a primeira etapa do curso de formação, além de responder à exigência da lei $n$. 11.350 , de 2006, que regulamenta a profissão de ACS, acaba atendendo também aos interesses dos gestores, que ao temerem a exigência de aumento salarial em função da formação técnica permanecem indiferentes à realização das demais etapas.

A crescente escolarização e profissionalização dos agentes de saúde contribuíram muito para o desempenho obtido na avaliação de competências de interpretação de texto e resolução de problemas. Em relação ao desempenho global, os resultados apontaram que quase a totalidade dos agentes de saúde de Campina Grande foi capaz de resolver adequadamente mais de $65 \%$ das questões e a metade deles respondeu adequadamente mais de $90 \%$ das perguntas, ou seja, fizeram 53 pontos ou mais. Ou seja, os agentes são capazes de responder as questões somente lendo os textos, sem outro recurso didático de apoio à aprendizagem. Se essa amostra é representativa da população de ACS da Paraíba e de outros estados, então podemos afirmar que metade dos agentes terá condições de compreender $90 \%$ da informação presente no material didático do Redpb. Considerando que ainda serão ofertadas videoaulas, então essa apropriação de conhecimento ainda pode ser maior.

Nas cidades do interior do estado, é provável que o perfil do ACS seja diferente daquele encontrado em Campina Grande, face ao fato de que esta cidade é a segunda maior do estado e um polo universitário. Os agentes de saúde com ensino fundamental apresentaram pior desempenho global na avaliação, o qual também foi influenciado pela sua idade, o fato do ACS ter ou não filhos, e o tempo de conclusão ou abandono do ensino formal. Geralmente pessoas com mais idade já constituíram família e têm filhos, assim como pararam de estudar há mais tempo, apresentaram pior desempenho global na avaliação. Ferraz e $\mathrm{Ganzo}^{42}$ afirmaram que, em relação à faixa etária, os agentes com mais idade têm seus próprios conceitos sobre o processo saúde-doença, advindos de experiências próprias ou alheias, podendo ser mais resistentes a novos conceitos relacionados à promoção da saúde em sua comunidade. Ou seja, quanto maior for a idade do ACS, mais barreiras serão encontradas para sua formação. Durante a aplicação do Redpb, por exemplo, espera-se que esses agentes cometam mais erros devido à sua menor compreensão do tema.

Quanto à pontuação nos grupos de competências gerais, verificou-se uma tendência de melhor desempenho dos agentes de saúde quando consideradas as questões de resolução de problemas em vez das de leitura e interpretação de texto. Essa dificuldade também foi relatada por Pedrosa et al. ${ }^{43}$ quando avaliaram os 337 ACS da Escola Técnica em Saúde da Universidade Federal da Paraíba, os quais, em alguns momentos do curso, tiveram de utilizar facilitadores para leitura dos textos e entendimento dos conceitos. Os agentes conseguem, portanto, lidar melhor com problemas práticos que estão vinculados com o seu cotidiano, em vez de interpretar textos ou aplicar conceitos.

Outro resultado muito interessante é que menos de 10\% dos ACS utilizam conhecimentos de "senso comum" para responder às questões propostas no Redpb e isto também pode ser resultado desse processo de escolarização e profissionalização. O agente parece ter deixado de ser um membro da comunidade no sentido do conjunto de ideias e crenças que ele utiliza para realizar o seu trabalho. O conhecimento científico passa a ser a moeda de troca do seu trabalho e isto tem sido visto como uma mudança positiva para alguns autores ${ }^{26}$; enquanto outros ${ }^{35,44,45}$ acreditam que o fato de ter mais conhecimento técnico não significa necessariamente mais vínculo e melhor atendimento para comunidade assistida por ele.

\section{Conclusão}

A metade da população amostrada de agentes comunitários de saúde foi capaz de responder adequadamente $90 \%$ das questões da avaliação. O seu desempenho global mostrou correlação positiva com a escolaridade e negativa com a idade, ter filhos e o tempo de conclusão do ensino formal. Os ACS possuem competências e habilidades de leitura e interpretação de texto que os habilitam à compreensão do material didático a ser usado pelo sistema de banco de dados do Redpb. O conjunto dos resultados aponta sua crescente escolarização e potencial para colaborar em pesquisas científicas fundamentais para estabelecimento generalizações sobre a saúde das populações. 


\section{Colaboradores}

JO Musse, RS Marques, FRL Lopes, KS Monteiro e SC Santos participaram igualmente de todas as etapas de elaboração do artigo.

\section{Referências}

1. Freitas FP, Pinto IC. Percepção da Equipe de Saúde da Família sobre a utilização do Sistema de Atenção Básica - SIAB. Revista Latino-am Enfermagem 2005; 13(4):547-554

2. Mello Jorge MHP, Laurenti R, Gotlieb SLT. A avaliação dos Sistemas de Informação em Saúde no Brasil. Cad Saúde Coletiva 2010; 18(1):7-18.

3. Oliveira QC. Sistema de Informação da Atenção Básica: análise do processo de produção de dados e informações em equipes de saúde da família de Cuiabá/MT [dissertação]. Cuiabá: Universidade Federal de Mato Grosso; 2010.

4. Marcolino JS, Scochi MJ. Informações em Saúde: o uso do SIAB pelos profissionais das Equipes de Saúde da Família. Rev. Gaúcha Enferm. 2011; 31(2):314-320.

5. Lima AP, Corrêa ACP, Oliveira QC. Conhecimento de Agentes Comunitários de Saúde sobre os instrumentos de coleta de dados do SIAB. Rev Brasileira de Enfermagem 2012; 65(1):121-127.

6. Bittar TO, Meneghim MC, Mialhe FL, Pereira AC, Fornazari DH. O Sistema de Informação da Atenção Básica como ferramenta da gestão em saúde. RFO 2009; 14(1):77-81.

7. Silva AS, Laprega, MR. Avaliação crítica do Sistema de Informação da Atenção Básica - SIAB e de sua implantação na região de Ribeirão Preto, São Paulo, Brasil. Cad Saude Publica 2005; 21(6):1821-1830.

8. Radiogonda B, Conchon MF, Nunes FPAN. Sistema de Informação da Atenção Básica e sua utilização pela equipe de saúde da família: uma revisão interativa. $R e$ vista Espaço para a Saúde 2010; 12(1):38-47.

9. Brasil. Ministério da Saúde (MS). Departamento de Atenção Básica. Teto, credenciamento e implantação das estratégias de Agentes Comunitários de Saúde, Saúde da Família e Saúde Bucal. [acessado 2012 mar 6]. Disponível em: http://dab.saude.gov.br/portaldab/historico_cobertura_sf.php

10. Brasil. Lei $n^{\circ} 10.507$ de 10 de julho de 2002. Dispõe sobre a criação da profissão de agente comunitário de saúde e dá outras providências. Diário Oficial da União 2002; 10 jul.

11. Brasil. Ministério da Saúde (MS). Ministério da Educação (MEC). Referencial curricular para curso técnico de agentes comunitários de saúde: área profissional saúde. Ministério da Saúde. Brasília: MS; 2004.

12. Maia ER, Pagliuca LMF, Oliveira WR. Competências do Agente Comunitário de Saúde junto à pessoa com deficiência: análise documental. Rev Enfermagem UERJ 2009; 17(4):485-490.

13. Anais do $10^{\circ}$ Congresso Brasileiro de Saúde Coletiva; 2012, Nov 14-18; Porto Alegre, Brasil. Rio Grande do Sul: Associação Brasileira de Saúde Coletiva. 2012.

14. Bernard HR. Social Research Methods. California: Sage; 2000.

15. Instituto Brasileiro de Geografia e Estatística (IBGE). [homepage na internet]. Censo demográfico 2010; características da população e do município de Campina Grande-PB. [acessado 2013 mar 27]. Disponível em: http: www.ibge.gov.br

16. Brandão IC, Martiniano CS, Monteiro AI, Marcolino MC, Brasil SCD, Sampaio J. Análise da Organização da Rede de Saúde da Paraíba a Partir do Modelo de Regionalização. Rev. Bras. Ciên. Saúde 2012; 16(3):347-352. 
17. Departamento de Atenção Básica. Ministério da Saúde [homepage na internet]. Teto, credenciamento e implantação das estratégias de Agentes Comunitários de Saúde, Saúde da Família e Saúde Bucal. Campina Grande. [acessado 2012 mar 6]. Disponível em: http://dab. saude.gov.br/portaldab/historico_cobertura_sf.php

18. Brasil. Ministério da Saúde (MS). Conselho Nacional de Saúde. Resolução no 196 de 10 de outubro de 1996. Diretrizes e Normas Regulamentadoras de Pesquisas Envolvendo Seres Humanos. Diário Oficial da União 1996; 16 out.

19. Souza LIM, Kok F, Santos S, Lucinio L, Lezirovitz K, Cavaçana N, Bueno C, Amorim S, Pessoa A, Graciani Z, Ferreira A, Prazeres A, Melo AN, Otto PA, Zatz M. New observations and linkage refining in spastic paraplegia, optic atrophy and neuropathy. Annals of Human Genetics 2009; 73:1-6.

20. Santos S, Kok F; Weller M.; Paiva FRL, Otto PA. Inbreeding levels in Northeast Brazil: Strategies for the prospecting of new genetic disorders. Genetics and Molecular Biology 2010; 33(2):10-16

21. Santos S, Melo US, Silva SLS, Weller M, Kok F. A endogamia explicaria a elevada prevalência de deficiências em populações do nordeste brasileiro? Cien Saude Colet 2012; 17(1):1-3.

22. Weller M, Soares MTO, Pereira JC, Almeida E S, Kok F, Santo S. Consanguineous unions and the burden of disability: a population-based study in communities of Northeastern Brazil. Am J Hum Biol 2012; 24(6):1-2.

23. Santos S; Pequeno AA, Galvão, CRC, Pessoa A, Almeida ES, Medeiros J, Kok F. As causas da deficiência física em municípios do Nordeste brasileiro e estimativa de custos de serviços especializados. Cien Saude Colet 2013; 19(1):1-2.

24. Santos MR. Perfil dos Agentes Comunitários de Saúde da Região de Juiz de Fora-MG [tese]. Rio de Janeiro: Universidade do Estado do Rio de Janeiro; 2006.

25. Maia ER, Almeida SB, Pagliuca LMF, Oliveira WR. Assistência à pessoa com deficiência: Competências do Agente Comunitário de Saúde. Rev Enfermagem UFPE 2009; 3(4):937-944.

26. Mota RRA, David HMSL. A Crescente Escolarização do Agente Comunitário de Saúde: uma indução do processo de trabalho Trab. Educ. Saúde 2010; 8(2):229-248.

27. Costa EM, Ferreira DLA. Percepções e Motivações de Agentes Comunitários de Saúde sobre processo de trabalho em Teresina, Piauí. Trab. Educ. Saúde 2012; 9(3):461-478.

28. Mialhe FL, Lefreve F, Lefevre AMC. O Agente comunitário de saúde e suas práticas educativas em saúde bucal: uma avaliação qualiquantitativa. Cien Saude Colet 2011; 16(11):4425-4432.

29. Santos KT, Saliba NA, Moimaz SAS, Arcieri RM, Carvalho ML. Agente comunitário de saúde: perfil adequado a realidade do Programa Saúde da Família? Cien Saude Colet 2011; 16(1):1023-1028.

30. Baralhas M, Pereira MAO. Concepções dos agentes comunitários de saúde sobre suas praticas assistenciais. Physis 2011; 21(1):31-46.

31. Lino MM, Lanzoni GMM, Albuquerque GL. Perfil Socioeconômico, demográfico e de trabalho dos Agentes Comunitários de Saúde. Cogitare Enfermagem 2012; 7(1):57-56.
32. Barbosa RHS, Menezes CAF, David HMSL, Bornstein VJ. Gender and healthcare work: a critical view of community health agents' work. Interface (Botucatu) 2012; 42(16):751-765.

33. Nascimento CMB. Análise do cumprimento das práticas dos Agentes Comunitários de Saúde em Municípios da Região Metropolitana de Recife [dissertação]. Recife: Centro de Pesquisas Aggeu Magalhães; 2008.

34. Galavote HS, Padro AN, Maciel ETT, Lima RCD. Desvendando os processos de trabalho do agente comunitário de saúde nos cenários revelados na Estratégia Saúde da Família no município de Vitória (ES, Brasil). Cien Saude Colet 2011; 16(1):231-240.

35. Gomes KO, Cotta RMM, Cherchiglia ML, Mitre SM, Batista RS. A Práxis do Agente Comunitário de Saúde no Contexto do Programa Saúde da Família: reflexões estratégicas. Saúde Soc 2009; 18(4):744-755.

36. Bornstein VJ. O agente comunitário de saúde na mediação de saberes [tese]. Rio de Janeiro: Escola Nacional de Saúde Pública Sergio Arouca; 2007.

37. Morosini MVGC. A Política de Formação dos Agentes Comunitários de Saúde: memória de uma formulação em disputa nos anos 2003-2005 [dissertação]. Rio de Janeiro: Universidade do Estado do Rio de Janeiro; 2009.

38. Barros DF, Barbieri AR, Ivo ML, Silva MG. O Contexto da formação dos Agentes Comunitários de Saúde no Brasil. Texto Contexto Enfermagem 2010; 19(1):78-84.

39. Vieira M, Durão AV, Lopes MR. Para além da comunidade: trabalho e qualificação dos agentes comunitários de saúde. Rio de Janeiro: Escola Politécnica de Saúde Joaquim Venâncio; 2011

40. Schubert J. Modos de Trabalho dos Agentes Comunitários de Saúde: entre o discurso institucional e o cotidiano de vulnerabilidade [dissertação]. Porto Alegre: Universidade Federal do Rio Grande do Sul; 2009.

41. Monteiro MAGS, Previtali FS. A política de formação profissional dos agentes comunitários de Saúde: limites e possibilidades de construção de sujeitos críticos. Re vista Labor 2011; 5(1):141-163.

42. Ferraz L, Ganzo CA. O cotidiano de trabalho do agente comunitário de saúde no PSF em Porto Alegre. Cien Saude Colet 2005; 10(2):347-355.

43. Pedrosa IL, Lira GA, Oliveira B, Silva MSML, Santos MB, Silva EA, Freire DMC. Uso de Metodologias Ativas na Formação Técnica do Agente Comunitários de Saúde. Tab. Educ. Saúde 2011; 9(2):319-323.

44. Marzari CK, Junges JR, Selli L. Agentes comunitários de saúde: perfil e formação. Cien Saude Colet 2011; 16(1):873-880.

45. Melo MCP, Coelho EAC. Integralidade e cuidado a grávidas adolescentes na Atenção Básica. Cien Saude Colet 2011; 16(5):2549-2558.

Artigo apresentado em 09/03/2014

Aprovado em 24/07/2014

Versão final apresentada em 26/07/2014 